\title{
Sistem Informasi Pendaftaran Online Pengujian Barang Dengan Penerapan Model Rapid Application Development (RAD)
}

\author{
Tri Retnasari \\ Teknik Informatika, Sekolah Tinggi Manajemen Informatika dan Komputer Nusa Mandiri Jakarta \\ e-mail: tri.trs@nusamandiri.ac.id

\begin{tabular}{ccc}
\hline Diterima & Direvisi & Disetujui \\
$03-01-2020$ & $24-01-2020$ & $05-02-2020$ \\
\hline
\end{tabular}

\begin{abstract}
Abstrak - Pemanfaatan teknologi informasi sebagai media komunikasi dan pertukaran informasi agar memperoleh informasi yang cepat, tepat serta akurat, sudah menjadi kebutuhan yang tidak terlepaskan pada saat ini. Pada unit pelayanan teknis pengujian mutu barang, teknologi informasi sangat dibutuhkan untuk mendokumentasikan informasi agar pada saat di butuhkan dokumen tersebut dapat segera memberikan informasi yang cepat, terpat serta akurat. Tujuan dari rancang bangun sistem informasi ini adalah untuk mempercepat petugas dalam melakukan pelayanan teknis pengujian mutu barang serta mempermudah masyarakat dalam mendapatkan informasi terhadap pengujian mutu barang. Balai Pengujian Mutu Barang (BPMB) membutuhkan solusi untuk mengatasi permasalahan yang terjadi. Solusi dari permasalahan yang tepat adalah dengan mengimplementasikan suatu sistem informasi pendaftaran online sehingga mempermudah Balai Pengujian Mutu Barang (BPMB) dalam memberikan pelayanan terutama pada teknis pengujian mutu barang dan melaksanakan pengembangan jasa pengujian serta meningkatkan sistem kinerjanya agar lebih optimal. Metode Penelitian menggunakan model Rapid Application Development (RAD), digunakan dengan alasan dimana fase dan aktivitas perancangan sistem yang di rancang lebih singkat untuk pembuatan proyek hanya membutuhkan waktu cukup singkat sekitar 2 bulan (60 hari) atau sampai 3 bulan (90 hari) sehingga menghasilkan rancangan SI/TI yang baik. Pemodelan sistem digambarkan dengan diagram pada Unified Modeling Language (UML). Rancangan sistem informasi sebagai media yang efektif dalam pengelolaan data, mempermudah petugas dalam melakukan pelayanan teknis pengujian mutu barang serta memberian informasi kepada masyarakat sebagai hasil akhir dari penelitian ini.
\end{abstract}

Kata Kunci: Pengujian Barang, Sistem Informasi, RAD

\begin{abstract}
The use of information technology as a medium of communication and information exchange in order to obtain information that is fast, accurate and accurate, has become an inseparable need at this time. In the technical service unit for testing the quality of goods, information technology is needed to document information so that when needed, these documents can immediately provide fast, accurate and accurate information. The purpose of the design of this information system is to speed up officers in conducting technical services testing the quality of goods and facilitate the public in obtaining information on testing the quality of goods. Balai Pengujian Mutu Barang (BPMB) needs a solution to overcome the problems that occur. The solution to the right problem is to implement an online registration information system so as to facilitate Balai Pengujian Mutu Barang (BPMB) in providing services especially in the technical quality testing of goods and carrying out the development of testing services and improving the performance system to be more optimal. The research method uses the Rapid Application Development (RAD) model, used for the reason that the system design phase and activities are designed to be shorter for project development which only takes a short amount of time around 2 months (60 days) or up to 3 months (90 days) to produce good SI / IT design. System modeling is illustrated by a diagram in the Unified Modeling Language (UML). The design of information systems as an effective media in data management, facilitates officers in conducting technical services testing the quality of goods as well as providing information to the public as the final result of this study.
\end{abstract}

Keywords: Goods Testing, Information Systems, RAD

\section{PENDAHULUAN}

Balai Pengujian Mutu Barang (BPMB) adalah unit pelayanan Teknis berada dibawah Direktotarat Pengembangan Mutu Barang (UPT
PMB). Balai Pengujian Mutu Barang (BPMB) memiliki tugas pokok memberikan pelayanan teknis pengujian mutu barang serta berfungsi untuk menyusun rencana dan program di bidang pengujian, 
memberikan pelayanan teknis pengujian mutu barang, melaksanakan pengembangan jasa pengujian.

Pada unit pelayanan teknis pengujian mutu barang, teknologi informasi sangat dibutuhkan untuk mendokumentasikan informasi agar pada saat di butuhkan dokumen tersebut dapat segera memberikan informasi yang cepat, terpat serta akurat. Untuk membuat sebuah perangkat lunak yang memiliki kinerja yang baik, dari tahap penerapan analisis dan implementasinya. Pemilihan metode analisis dan perancangan yang tepat akan memberikan kemudahan dalam membangun sistem informasi (Kosasi \& Yuliani, 2015).

Tahapan perancangan sistem pada model Rapid Application Development lebih singkat sehingga menghasilkan sistem informasi yang baik. Lama perancangan pada proyek SI/TI dibutuhkan lama waktu minimal 6 bulan (180 hari), sedangkan dengan penerapan model Rapid Application Development lama waktu dibutuhkan untuk menyelesaikan sistem perangkat lunak hanya 30-90 hari (Kosasi, 2015). Tahapan dalam merancang sebuah proyek SI/TI dengan model Rapid Application Development dapat lebih cepat sehingga dapat menghasilkan rancangan SI/TI yang baik (Aswati \& Siagian, 2016). Rapid Application Development merupakan model untuk melakukan perancangan perangkat lunak secara linier dalam waktu yang sangat singkat (Fadli, 2018).

Model rekayasa perangkat lunak secara bertahap namun teratur yang diatur dengan waktu pengembangan SI/TI yang sangat singkat merupakan model dari Rapid Application Development. Model Rapid Application Development merupakan adaptasi dari model waterfall namun dengan tingkat perancangan dengan "kecepatan tinggi”, dengan maksud perkembangan yang dilakukan pencapaian dengan menggunakan pemograman berbasis komponen. Setelah dilakukan analisa terhadap kebutuhan organisasi serta ruang lingkup pengembangan SI/TI dapat diidentifikasikan, proses Rapid Application Development memberikan arahan kepada para tim pengembang SI/TI agar dapat mengembangkan atau mmenciptakan SI/TI sesuai kebutuhan dengan proses dalam lama waktu cukup relatif cepat (Pressman, 2012). Rapid Application Development (RAD) merupakan metodologi yang lengkap, dengan 4 fase siklus hidup yang sejajar dengan fase SDLC tradisional, fase dan aktivitas Rapid Application Development (RAD) digambarkan pada pada gambar dibawah ini.

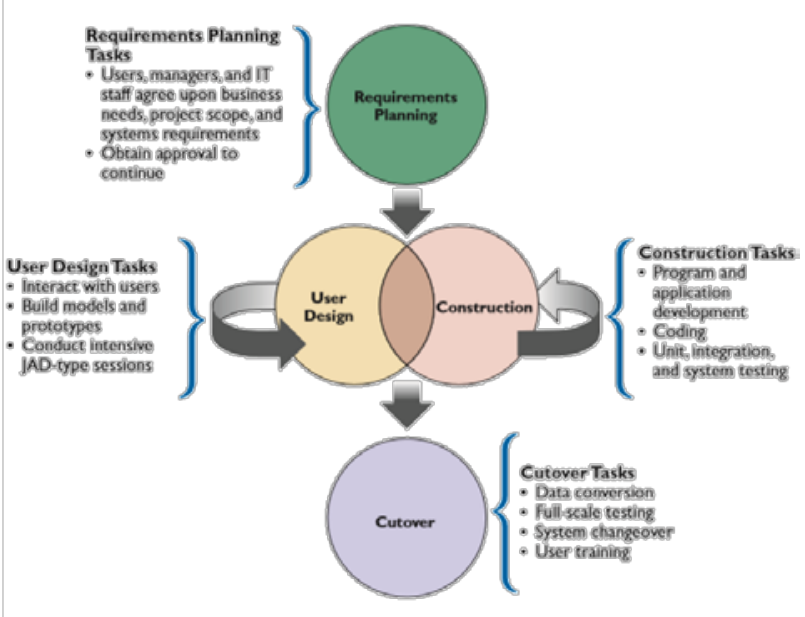

Sumber: Shelly (2012)

Gambar 1. Model Rapid Application Development

Empat fase dalam Rapid Application Development (RAD) yang dimulai dari analisis kebutuhan pengguna, perancangan, sampai dengan penerapan. Berikut adalah tahapan pengembangan aplikasi dari tiap fase dan aktivitas dalam Rapid Application Development (RAD):

\section{Requirements Planning}

Aktivitas pada tahap ini, dilakukan analisis yang dengan cara pertemuan antara pengguna serta analis sistem untuk mengidentifikasikan kebutuhan organisasi/perusahaan serta tujuan dari SI/TI yang akan dibuat. Fokus pada fase ini adalah hasil dari analisa sistem dapat menyelesaikan masalah yang terjadi di organisasi/perusahaan. Teknologi informasi dan sistem informasi dapat diarahkan meskipun hanya sebagian dari sistem, fokusnya tetap untuk mengupayakan solusi terhadap permasalahan yang terjadi di perusahaan atau organisasi (Kendall \& Kendall, 2010).

2. User Design

Aktivitas User Design adalah tahapan untuk merancang serta memperbaiki sistem sebelumnya. Analis sistem serta pemrogrammer bekerja sama membangun desain sistem informasi yang dikembangkan beserta pola kerja kepada pengguna nantinya. Selama perancangan desain dengan Rapid Application Development (RAD), pengguna melakukan pemeriksaan terhadap prototype yang ada dan Analis sistem akan memperbaiki berdasarkan koreksi dari pengguna (Kendall \& Kendall, 2010)

3. Construction

Pada tahap implementasi, analis sistem bekerja sama dengan pengguna dengan cara berkomunikasi terus menerus dan merancang kebutuhan organisasi/perusahaan yang dibutuhkan. Setelah rancangan disetujui maka akan langsung dilakukan pembangunan atau konstruksi terhadap sistem-sistem yang akan dibangun, sistem yang baru dibangun kemudian 
akan diujicoba setelah itu diperkenalkan kepada perusahaan atau organisasi yang akan menggunakan sistem tersebut (Kendall \& Kendall, 2010).

\section{Cutover}

Merupakan tahapan peralihan, dimana pada aktivitas ini dilakukan perubahan secara langsung antara sistem lama secara langsung digantikan dengan sistem baru termasuk konversi data.

\section{METODE PENELITIAN}

Tahapan dalam kerangka penelitian dibagi menjadi 4 fase, dimana terdapat fase dan aktivitas yang terdapat dalam Rapid Application Development (RAD):

1. Perencanaan kebutuhan

Tahapan ini menggabungkan elemen-elemen perencanaan sistem dan fase analisis SDLC. Menganalisa prosedur yang ada kemuadian bagian yang terkait dengan sistem mendiskusikan dan menyetujui kebutuhan bisnis, ruang lingkup proyek, serta kendala yang terjadi.

2. Desain pengguna

Selama tahap ini, dilakukan pengembangan dengan model serta prototype yaitu input, proses, output. Proses design mengalokasikan kebutuhan untuk membangun arsitektur sistem secara keseluruhan. Penulis menggunakan Unfied Modelling Language (UML) sebagai visualisasi, merancang dan mendokumentasikan sistem piranti lunak.

3. Konstruksi

Tahap konstruksi menekankan pada tugas pengembangan program sistem informasi yang menyerupai tahapan SDLC. Pembuatan code program (Dreamweaver CS5), Pengolahan database (MySQL), Script untuk penjelajah web (Javascript), serta Debugging dan Profilling.

4. Cutover

Tahap dimana sistem lama langsung di ubah dengan sistem yang baru termasuk konversi data, pengujian, dan pelatihan pengguna. Mengintegrasikan serta menguji Programprogram sebagai sistem yang lengkap, untuk mengetahui apakah kebutuhan terhadap SI/TI telah terpenuhi.

\section{HASIL DAN PEMBAHASAN}

\section{Tahap Analisa Prosedur Berjalan Pelayanan} Teknis Pengujian Barang

a. Pelanggan mengajukan permohonan pengujian, petugas seksi pelayanan teknis (SPT) menerima permohonan dan melakukan verifikasi sample pengujian, setelah diverifikasi Petugas spt berwenang menerima dan menolak sample, jika sample sesuai dengan parameter uji/kriteria akan diterima, selain itu ditolak.

b. Petugas SPT membuatkan tanda terima contoh dan mencantumkan harga,metode penilitian kemudiandiberikan ke pelanggan.

c. Petugas SPT menginput surat permohonan kedalam database/aplikasi BPMB untuk dibuatkan SPK (Surat Perintah Kerja).

d. Petugas spt menginput data perusahaan kedalam database/aplikasi BPMB, dan menerbitkan surat perintah kerja kepada petugas laboratorium yang sesuai dengan parameter uji sample yang akan di uji

e. Laboratorium menguji sample, lalu laboratorium menerbitkan sertifikat yang telah ditandatangani oleh kepala balai pengujian,kemudian sesuai dengan janji yang telah disepakati pelanggan mengambil setifikat dengan menyerahkan bukti pembayaran dan membawa Tanda terima.

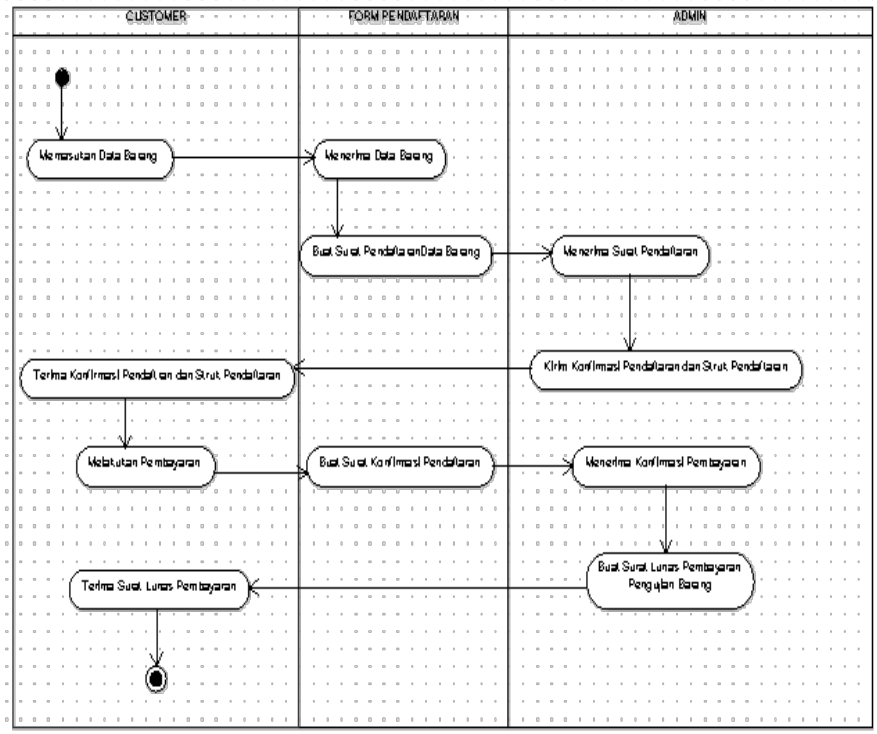

Gambar 2. Pendaftaran Barang (Activity Diagram)

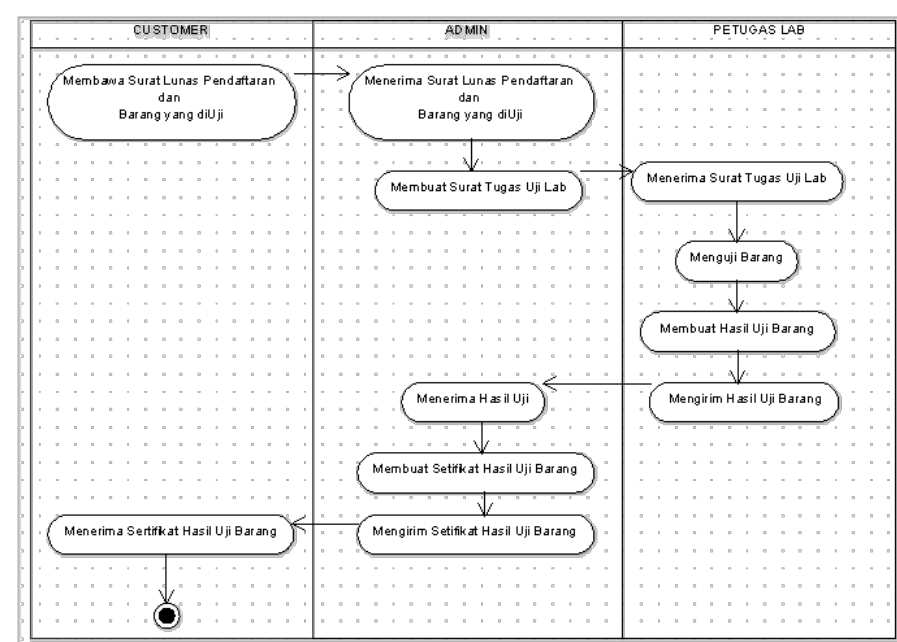

Gambar 3. Pengujian Barang (Activity Diagram) 


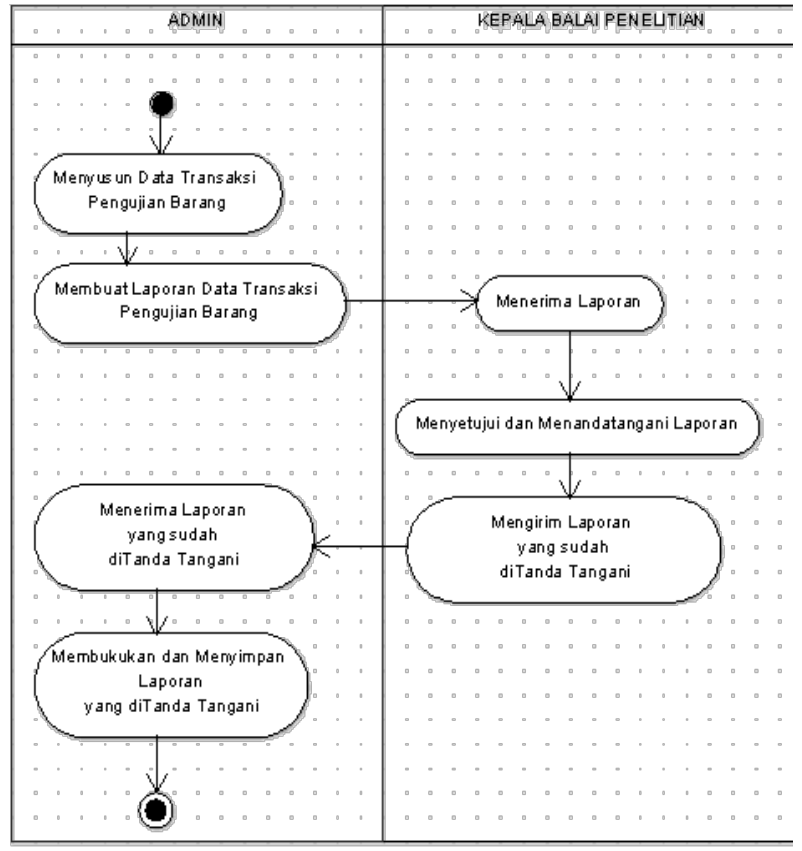

Gambar 4. Laporan Uji Barang (Activity Diagram)

\section{Tahap Rencana Kebutuhan (Requirement Planning)}

a. Kebutuhan Fungsional

Kebutuhan user interface (antar muka) untuk pengoprasian sistem informasi pendaftaran online pengujian barang. Secara fisik, user interface (antar muka) yang dirancang adalah tampilan menu pilihan, form isian dan laporan terkait dengan sistem terhadap data yang akan diolah yaitu pendaftaran user, pendaftaran pengujian barang, dan laporan hasil pengujian barang.

b. Kebutuhan Non-Fungsional

Kebutuhan Software: Sistem Operasi Microsoft Windows XP Service Pack, Wamp Server 2.0, browser. Kebutuhan Input: Data user, Data pendaftaran pengujian barang. Kebutuhan Informasi Laporan hasil pengujian barang.

\section{Tahap Desain Sistem}

Pada tahap desain sistem, untuk pemodelan sistem pendaftaran online pengujian barang ini dengan rancangan diagram use case. Diagram use case menjelaskan terdapat aktivitas yang terjadi di pada sistem atau apa kelas dan siapa actor yang berinteraksi mengolah atau melakukan aktivitas tersebut. Pada diagram use case sistem pendaftaran online pengujian barang sebagai actor yaitu Admin, Customer, Kepala Seksi Pengujian (Gambar 5).

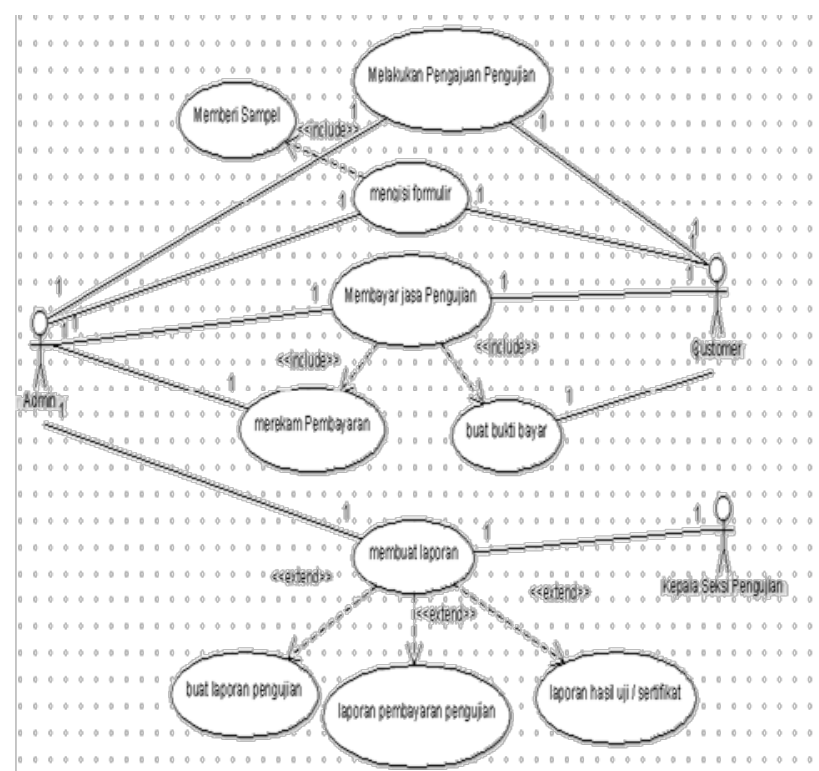

Gambar 5. Diagram Use Case Sistem Pendaftaran Online Pengujian Barang

Diagram Sequence menggambarkan interaksi antar user, objek serta sistem yang ada di dalam dan di sekitar sistem. Interaksi yang terjadi dapat digambarkan berupa pesan dan waktu proses pengerjaan (Gambar 6 dan Gambar 7).

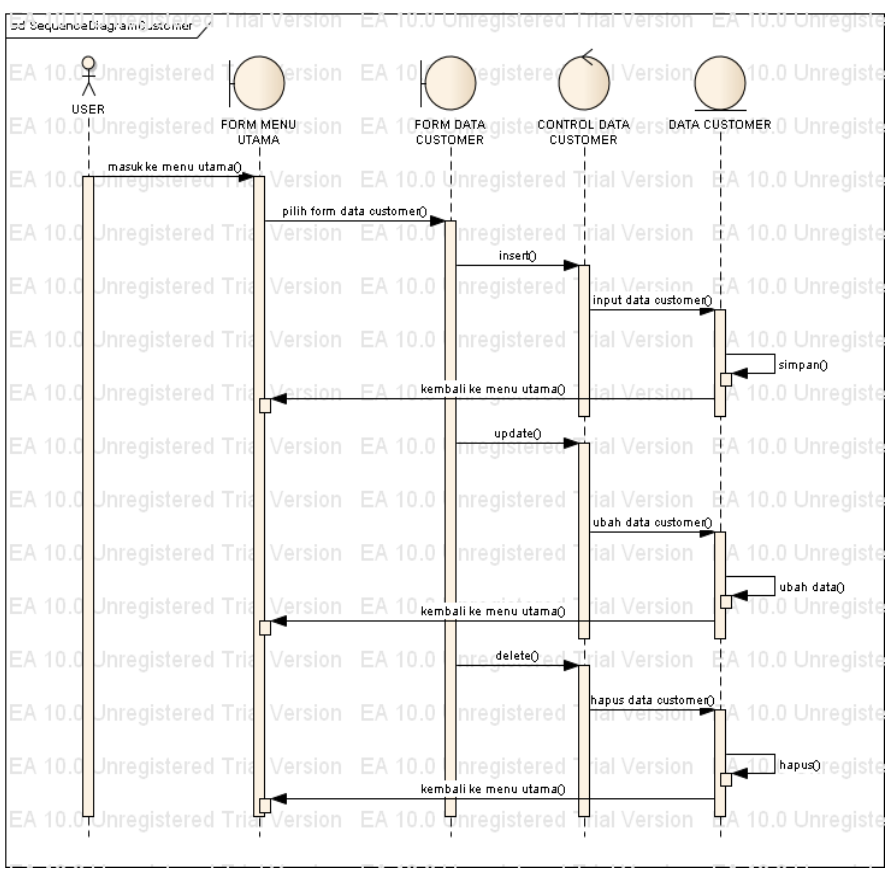

Gambar 6. Sistem Daftar User (Diagram Sequence) 


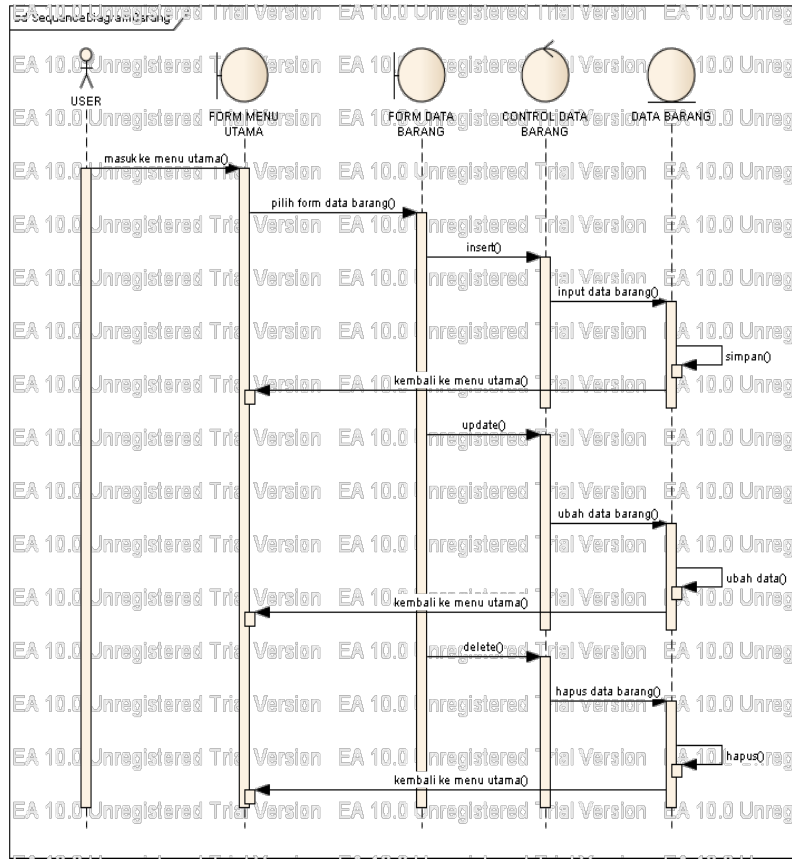

Gambar 7. Sistem Pendaftaran Pengujian Barang (Diagram Sequence)

Berikutnya, untuk seluruh pesan yang masuk kedalam sistem akan dipetakan menjadi operasi dari class (Gambar 8).

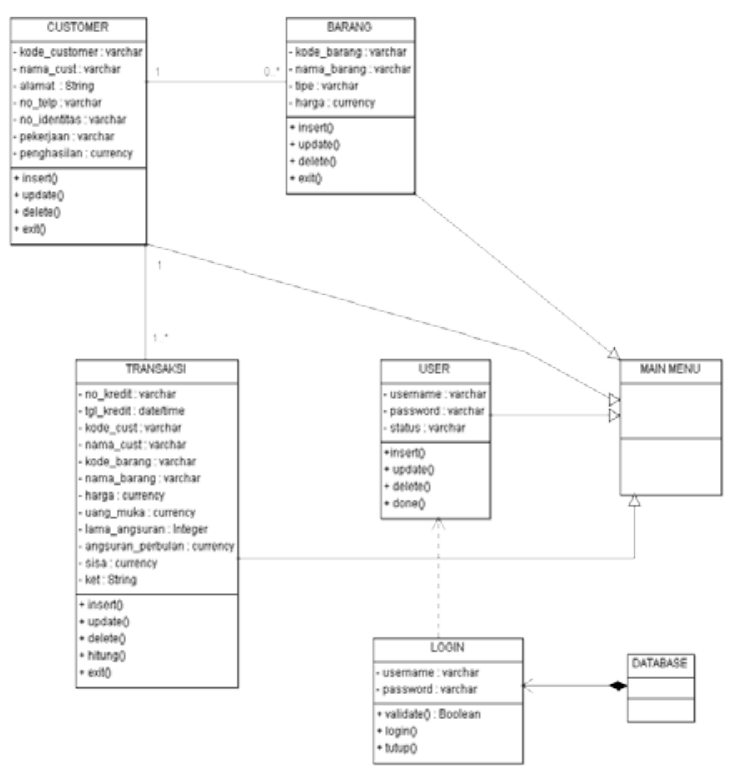

Gambar 8. Diagram Class Sistem Pendaftaran Online Pengujian Barang

\section{Tahap Implementasi}

Pada tahap implementasi yaitu mewujudkan desain sebagai sebuah program. Hasil implementasi dapat ditunjukkan dengan gambar dibawah ini:

\section{SELAMAT DATANG DI WEBSITE KAMI}

\section{LOGIN}

Username

Password

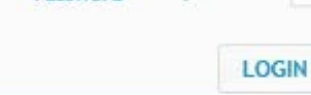

Klik disini untuk mendaftar

Gambar 9. Form Login

Silahkan isi data dibawah ini

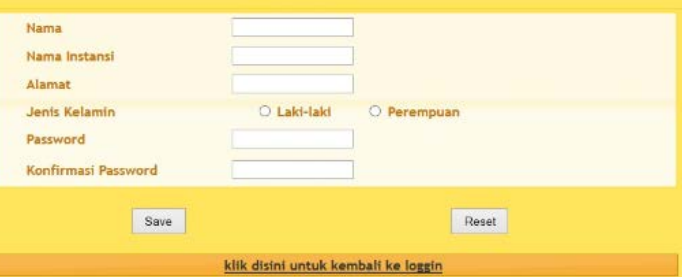

Gambar 10. Form Daftar User

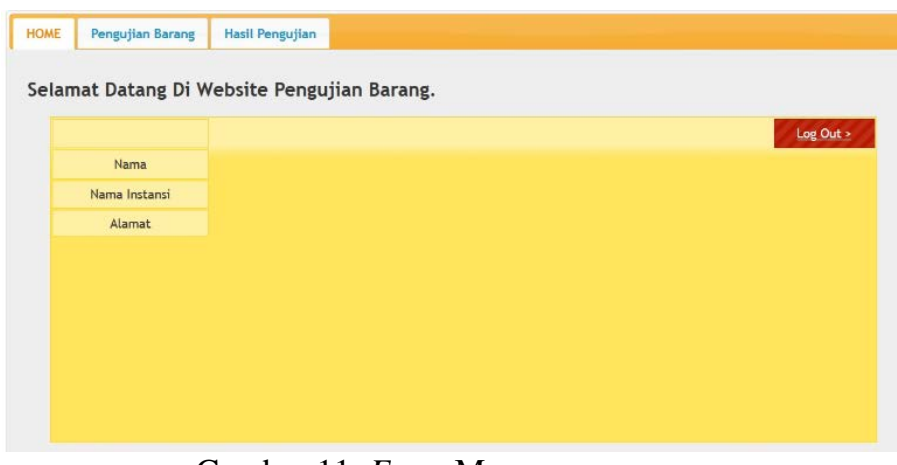

Gambar 11. Form Menu

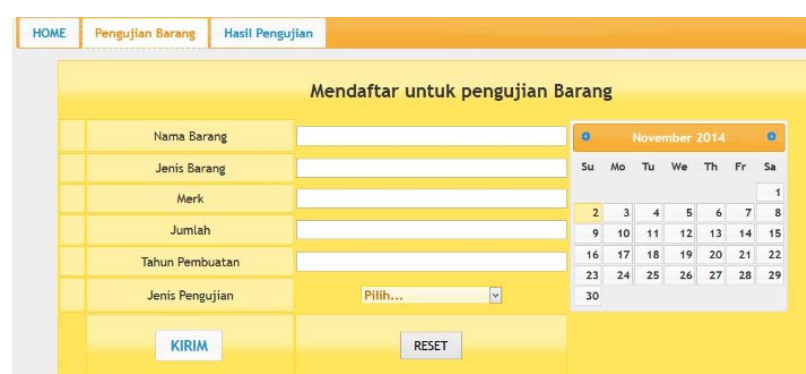

Gambar 12. Form Pendaftaran Pengujian Barang 


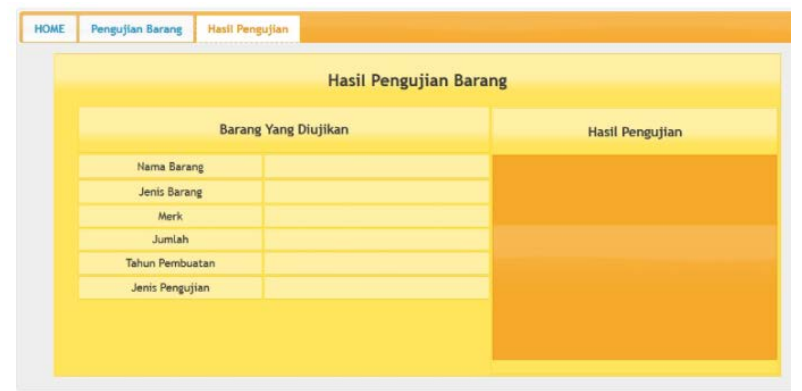

Gambar 13. Form Hasil Pengujian Barang

\section{KESIMPULAN}

Dari analisis hingga implementasi sistem, maka penulis mengambil beberapa poin kesimpulan sebagai berikut: Sistem informasi pendaftaran online pengujian barang yang penulis buat, nantinya akan dapat membantu Balai Pengujian Mutu Barang (BPMB) dalam melaksanakan pekerjaan mereka dalam memberikan pelayanan teknis pengujian mutu barang. Penerapan metode Rapid Application Development (RAD) dalam menghasilkan SI/TI pendaftaran online pengujian barang sudah dapat memberikan hasil yang maksimal. Sistem dianggap dapat memenuhi kebutuhan Balai Pengujian Mutu Barang (BPMB) dalam memberikan pelayanan teknis pengujian mutu barang, melaksanakan pengembangan jasa pengujian dan melaksanakan urusan tata usaha dan rumah tangga sehingga mempermudah masyarakat untuk mendapatkan informasi. Setiap tahapan penyelesaianpada perancangan sistem informasi pendaftaran online pengujian barang mengikuti fase dan aktivitas yang ada dalam model Rapid Application Development yaitu Requirements Planning, User Design, Construction dan Cutover.

\section{REFERENSI}

Aswati, S., \& Siagian, Y. (2016). Model Rapid Application Development Dalam Rancang Bangun Sistem Informasi Pemasaran Rumah (Studi Kasus : Perum Perumnas Cabang Medan). Seminar Nasional Sistem Informasi Indonesia (pp. 317-324). Surabaya: SESINDO.

Fadli, S. (2018). Model Rapid Application Development Dalam Pengembangan Sistem Reservasi Dan Penyewaan Kamar Hotel. JIRE (Jurnal Informatika \& Rekayasa Elektronika), 54-64.

Ichsan. (2013). Sistem Pendukung Keputusan Pemilihan Penerima Beasiswa Mahasiswa Kurang Mampu Pada STMIK BUDIDARMA Medan Menerapkan Metode Profile Matching. Kursor , 5 (1), 2.

Kendall, J., \& Kendall, K. (2010). Analisis dan Perancangan Sistem. Jakarta: Indeks.

Kosasi, S. (2015). Penerapan Rapid Application Development Dalam Sistem Perniagaan Elektronik Furniture. Citec Journal, Vol. 2 No. 4 , 265-276.

Kosasi, S., \& Yuliani, I. D. (2015). Penerapan Rapid Application Development Pada Sistem Penjualan Sepeda Online. Jurnal SIMETRIS , 27-36.

Pressman, R. (2012). Rekayasa Perangkat Lunak: Pendekatan Praktisi. Yogyakarta: Andi Offset.

Shelly, G., \& Harry, J. (2012). System Analysis and Design, Ninth Edition. Boston: Cengage Learning. 